\title{
СТРОЕНИЕ И РАЗВИТИЕ ЗОЛЛЯ СИНИАЛЛИКА НА ДРУМЛИНЕ ЛАЙЗЕ
}

Среди форм рельефа, осложняющих поверхность крупных Саадъярвски, друмлинов (Восточная Эстония), группами встречаются золли - небольшие, преимущественно округлые блюдщеобразные воронки. Они обычно заполнены торфом и/или водой («мокрые» золли), но иногда имеют на дне и склонах лишь делювий мощностью до нескольких метров («сухие» золли).

Наибольшей известностью из золлей Саадъярвского друмлинового поля пользуется относительно крупная впадина-ванна в Лайузе (золль Синиаллика). Она находится на вершинной части Лайузеского друмлина (абсолютная высота 144, относительная - 60 м) в 0,5 км юго-восточнее от шоссе Иыгева-Муствеэ. Золль имеет слегка продолговатую с севера-северо-запада на юг-юго-восток форму, его дно заполнено низинным болотом, поросшим низким березовым кустарником, и лишь в центральной части наблюдается небольшой участок переходного болота со сфагновыми кочками. Площадь заболоченной части золля $11000 \mathrm{~m}^{2}$ $(130 \times 90$ м $)$. В центральной части болота находится легендарный ключ Синиалликас (в переводе с эстонского - голубой ключ). Севернее и южнее Синиалликаского золля цепью расположено множество более мелких как «мокрых», так и «сухих» золлей. Изучение этих микроформ рельефа представляет интерес при выяснении морфогенетических процессов во время деградации материкового льда, а также при выявлении специфики позднеледниковой и раннеголоценовой палеогеографии.

О морфологии, геологическом строении и развитии золлей Саадъярвского друмлинового поля до последнего времени имелись лишь скудные и отрывочные данные. Так сообщалось, что в золле Синиаллика верхний, «водянистый» торф мощностью 3 м подстилается двухметровым слоем «иловатого» торфа (Lillema, 1958).

Летом 1979 и 1981 гг. авторами проведено бурение (рис. 1) Синиалликаского золля. Золль довольно крутосклонный (в среднем $17-18^{\circ}$ ), его глубина $12-13$ м, он почти до краев заполнен торфом. Скважины прошли максимально 11,6 м торфяной залежи, ниже которой в центральной части воронки был вскрыт маломощный $(0,7$ м) слой пелитового алеврита. На склонах воронки алевритовые отложения имеют мощность от $0,15 \mathrm{M}$ (скв. 4) до $1,8 \mathrm{~m}$ (скв. 3) и подстилаются водонасыщенной суглинистой мореной. По краям заболоченной части золля проходит невысокая (до 0,7 м) пахотная терраса, сформировавшаяся в результате техногенной эрозии почв.

Четвертичный покров в самой высокой части друмлина Лайузе представлен в основном супесчаной и суглинистой мореной последнего оледенения, перекрытой либо маломощным слоем (в среднем 0,3-0,4 м) покровной супеси проблематичного генезиса, либо спорадически распространенным флювиогляциальным гравистым песком (до 0,7 м, в основном к востоку от золля). Местами морена на вершине друмлина почти отсутствует (напр., к северу от описываемой впадины), местами же достигает 21 м. Морена подстилается гра авийноядесчаными отложениями 
последнего оледенения мощностью порядка 20 м (Каяк, 1965). Верхние $1-2$ м морены рыхлые опесчаненные и представляют собой, по всей вероятности, ее абляционную разновидность.

В центральной части воронки залежь торфа характеризуется мозаичным и исключительно сложным строением из-за чередования разных видов низинного торфа как в вертикальном, так и горизонтальном направлениях. На терригенных алевритовых отложениях залегает прослойка хорошо разложившегося древесного торфа мощностью 5-15 см. В самой нижней и более разложившейся части эта прослойка напоминает маломощный горизонт лесного сырого (грубого) гумуса. Следы почвообразовательных процессов макроскопически прослеживаются также в верхней части алеврита (скв. II, 1, 2). Вышележащие слои представлены в основном тростниковым, гипновым и сфагновым торфами и различными переходными между ними типами (тростниково-гипновым, гипново-тростниковым, сфагново-тростниковым, пушицево-сфагновым торфами и т. д.). Местами встречаются также остатки осок, реже хвоща. Мощность прослоек чередующихся разных видов торфа составляет часто лишь $3-10 \mathrm{~cm}$.

Аналогично чередованию состава меняется и степень разложения торфа. Так в нижней части центра залежи (напр., скв. II на глубинах $10,5-11,5$ м) торф имеет более высокую степень разложения $(30-50 \%)$, чем перекрывающая его толща, где преобладают прослои слабо-и среднеразложившегося торфа; в пределах верхнего 1,5 м встречается слаборазложившийся торф (скв. I, 1, 7). В более глубокой части залежи (12 м) находятся маломощные прослойки (2-3 мм) и пачки коричневого сапропеля, а также более мощные слои сапропелевого тростникового торфа. В скв. 1 (рис. 2) установлена линза сапропеля оливкового цвета мощностью 1,0 м.

В краевой части золля залежь торфа по составу более однородна. Там преобладают осоковый и гипново-осоковый, а в низах - древесногипновый и древесный торфы. Такие понижения на холмистой местности и во флювиогляциальных отложениях обычно считаются реликтовыми воронками термокарстового (Whittlesey, 1860; Mannerfelt, 1945; и др.) или эворзионного происхождения (Kudaba, 1964; и др.). В морене они встречаются реже, имеют более неправильную форму и их труднее отличить от замкнутых понижений иного генезиса (Flint, 1971).

Можно согласиться с утверждением, что Синиалликаский золль имеет термокарстовое (гляциокарстовое) происхождение. Его образование следует связывать с таянием довольно крупной глыбы льда, полностью погребенной в морене после деградации ледника. Отделение глыбы произошло, видимо, в начале среднего дриаса. Многие авторы оценивают сохранение погребенного льда в поздне- и послеледниковое время тысячами лет (Сейбутис, 1962, 1970; Clayton, 1967; и др.). При этом А. Сейбутис (1970) утверждает, что деградация погребенного льда на территории Литвы завершилась не раньше пребореального климатического периода. Данные по Юго-Восточной Эстонии показывают, что там в процессе формирования холмисто-западинного рельефа погребенные льды растаяли в позднеледниковое время (Карукяпп, 1979).

Рассматривая генезис и развитие золля Синиаллика, необходимо обратить внимание на следующие обстоятельства.

В алевритовых отложениях содержится крайне мало пыльцы (в их составе обнаружены даже отдельные пыльцевые зерна сосны, березы, ольхи, ильма) и спор Polypodiaceae, которые явно переотложены из морены. Только в самой верхней прослойке алеврита, под торфом, пыльщы встречается больше: сосны и березы $46 \%$, ольхи $6 \%$, ильма и ивы $2 \%$, найдены также единичные пыльцевые зерна Cyperaceae, Caryophyllaceae и Onagraceae; присутствуют споры Polypodiaceae $(160 \%)$ и лесотундровых 
видов Selaginella selaginoides и Botrychium boreale, которые могли расти в самом начале пребореального климатического периода в луговых кустарниковых сообществах. Так как в алевритовых отложениях данной воронки пыльцевые зерна травянистых растений, характерные позднеледниковым озерным отложениям Саадъярвского друмлинового поля (Пиррус, 1969, 1971; Pirrus, Rõuk, 1979), почти полностью отсутствуют, можно предполагать, что они заполнили неглубокое пологосклоновое понижение на месте нынешнего золля сразу после освобождения друмлина Лайузе из-под ледника, в период, когда местная растительность практически еще отсутствовала.

Существенного таяния погребенной ледяной глыбы в течение позднеледниковья, по-видимому, еще не произошло, и небольшое суходольное понижение, сглаженное алевритовыми отложениями, в рельефе почти не выделялось. В начале пребореального климатического периода понижение покрылось редким кустарником и березовым лесом и позже заболотилось. Это и знаменует начало более интенсивного таяния ледяной глыбы, а в то же время и заложение воронки. Но лишь в бореальном климатическом периоде началось еще более быстрое проседание грунта над тающей глыбой, которое в какой-то мере продолжалось и в первую половину атлантического климатического периода. На проседание грунта и образование начальной воронки указывают виды торфа, накопившиеся в насыщенной влагой среде, присутствие сапропелевых прослоек, и особенно, распределение одновозрастных слоев торфа на разных глубинах (рис. 2). Так, например: 1) в центральной, более глубокой части золля поверхность пребореального слоя торфа залегает примерно на 2 м ниже, чем в краевой части воронки; 2) разница в глубине залегания слоев торфа, соответствующих границе между ВО2 и АТ1 палинозонами (рис. 2) также достигает примерно 2 м; 3) разница в глубине залегания слоев торфа, соответствующих границе между AT1 и АТ2 палинозонами, уже малозаметна, и можно предположить, что к этому времени термокарстовая воронка приобрела близкую к настоящему времени морфометрию.

В дальнейшем накопление низинного торфа продолжалось до конца $\mathrm{SB} 2$, которое уже в конце AT2 в центре воронки сменилось образованием торфа переходного типа.

Условия для образования ключа на дне воронки возникли предположительно не раньше бореального климатического периода.

Стратиграфическое расчленение отложений, объясняющее развитие золля, основывается на данных палинологического изучения (рис. 3,4 ) и радиоуглеродного датирования скважин (рис. 4).

Составленные спорово-пыльцевые диаграммы хорошо коррелируют между собой и имеют черты, свойственные диаграммам озерных голоценовых отложений Саадъярвского друмлинового поля (Pirrus, Rõuk, 1979). Основными из них являются: a) низкое содержание пыльцы сосны по всему разрезу голоцена; б) скромное содержание пыльцы сосны по сравнению с содержанием пыльцы березы даже в отложениях бореальной климатической стадии (в других диаграммах с территории Эстонии обнаруживается максимум содержания пыльцы сосны); в) относительно высокое содержание пыльцы широколиственных пород в отложениях атлантической климатической стадии. Благодаря распространению плодородных почв и специфике геолого-геоморфологических условий друмлиновое поле и в настоящее время выделяется как самостоятельный геоботанический подрайон (Laasimer, 1965).

По сравнению с Саадъярвским друмлиновым полем в целом, отличительной чертой спорово-пыльцевого состава рассматриваемых разрезов является относительно высокое содержание пыльцы лещины (до $50 \%$ ), а в некоторой мере также широколиственных пород. Это, вероятно, обусловлено особенностями палеорастительности в окрестностях золля. 
Признаком ранней сельскохозяйственной деятельности человека следует считать появление пыльцы культурных видов злаковых (рис. 3 , 4), сопровождаемое увеличением количества пыльцы как рудеральных растений, так и разнотравья (Chenopodium album, Artemisia, Compositae, Plantago, Polygonaceae, Onagraceae, Umbelliferae и др.) уже в начале SA1 палинозоны.

Подводя итоги, можно сказать, что просадки, вызвавшие образование золля в Синиаллика, начались, вероятно, в начале пребореального климатического периода, хотя небольшое проседание грунта могло произойти уже раньше, возможно, в аллереде и в позднем дриасе («немые» отложения на дне золля). В дальнейшем формирование воронки в связи с улучшением климата протекало относительно быстрее и завершилось в основном в атлантический климатический период. Оплывание склонов и эрозионно-делювиальные процессы, сопровождавшие просадки, имели в морфогенезе воронки несущественное значение, очевидно, из-за закрепления склонов воронки растительностью, по сравнению с тем, если бы просадки имели место в палеогеографических условиях позднеледниковья. Морфология золля постепенно изменена лишь болотными процессами, продолжавшимися до настоящего времени. Следовательно, ведущую роль в образовании изученного нами золля Синиаллика играли гляциокарстовые процессы. Однако такое объяснение при рассмотрении генезиса остальных небольших замкнутых впадин на друмлине Лайузе не следует считать определяющим. Их палинологическое изучение дает информацию о характере более локальной палеорастительности, чем изучение отложений междрумлиновых озер.

\section{ЛИТЕРА Т РА А}

Карукяпn Р. Я. Особенности формирования четвертичного покрова и форм рельефа в готигляциальном этапе дегляциации (на примере территории Эстонии). - Дис. канд. геол.-мннер. н. Таллин, 1979.

Каяк К. Ф. К геологии Саадъярвского друмлинового поля. - В кн.: Литология и стратиграфия четвертичных отложений Эстонин. Таллин, 1965, 23-29.

Каяк K., Кессел Х., Лийвранд Э., Пиррус Р., Раукас А., Сарв А. Стратиграфия четвертичных отложений Эстонин. - В кн.: Стратиграфия четвертичных отложений Прнбалтикн. Вильнюс, 1976, 4-52.

Пиррус Р. Стратиграфнческое расчленение позднеледниковых отложений Южной Эстонии по данным спорово-пыльцевого анализа. - Изв. АН ЭССР. Хим. Геол., 1969, 18, № 2, 181-190.

Пиррус Р. О. О результатах количественного видового анализа пыльцы и спор при изучении позднеледниковых отложений на примере разреза Визусти (Южная Эстония). $\rightarrow$ В кн.: Палинологические исследования в Прибалтике. Рига, 1971, $127-133$.

Сейбутис A. О стратиграфическом значении двухслойных торфянистых подсапропелевых образований. - Тр. АН ЛитССР, сер. Б, 1962, 30, № 3, 173-178.

Сейбутис А. О чередовании болото- и озерообразовательных процессов в голоцене. - В кн.: История озер. II. Внльнюс, 1970, 444-450.

Clayton, L. Stagnant Glacier Features of the Missouri Coteau and Adjacent Areas. Grand Forks, North Dakota, 1967, 25-43.

Flint, R. F. Glacial and Quaternary Geology. New York, 1971.

Kudaba, C. Kai kurios pastabos apie rinu kilme Dzūkijos aukštumose. - Lietuvos TSR Aukštuju mokyklu Mokslo darbai. Geografija ir geologija. III. Vilnius, 1964.

Laasimer, L. Eesti NSV taimkate. Tallinn, 1965.

Lillema, A. Eesti NSV mullastik. Tallinn, 1958.

Mannerfelt, C. M. Nagra glacialmorfologiska formelement och deras vittnesbörd om inlandsisens . avsmältningsmekanik i Svensk och Norsk fjällterräng. - In: Geografiska Annaler. Stockholm, 1945, h. $1-2$. 


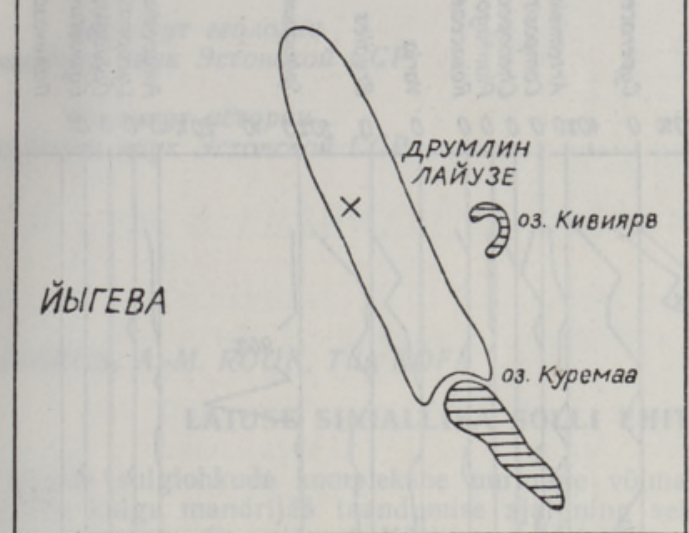

Рис. 1. Схема расположения золля Синиаллика на друмлине Лайузе.

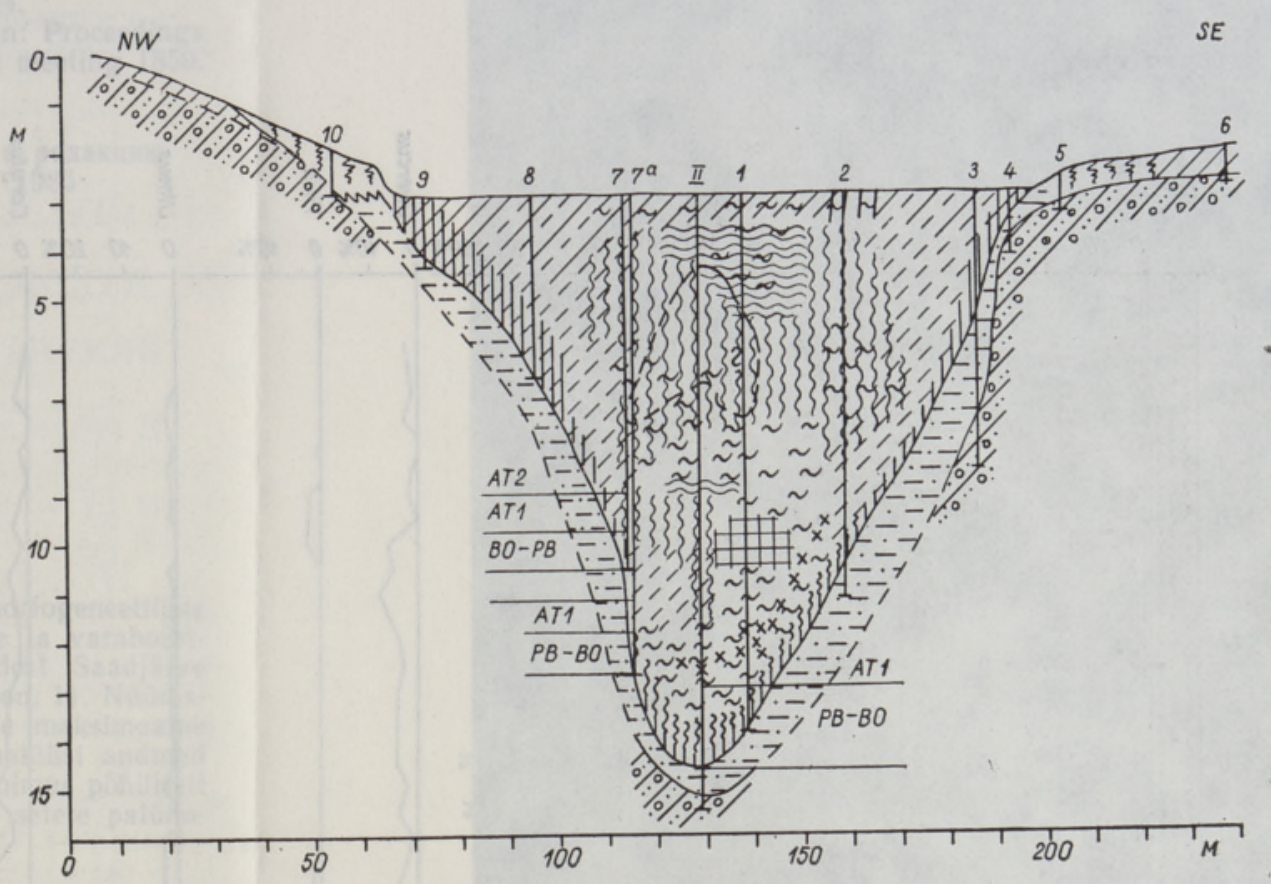

Рис. 2. Поперечный профиль отложений золля Синиаллика. Усл. обозн. см. на рис. 3.

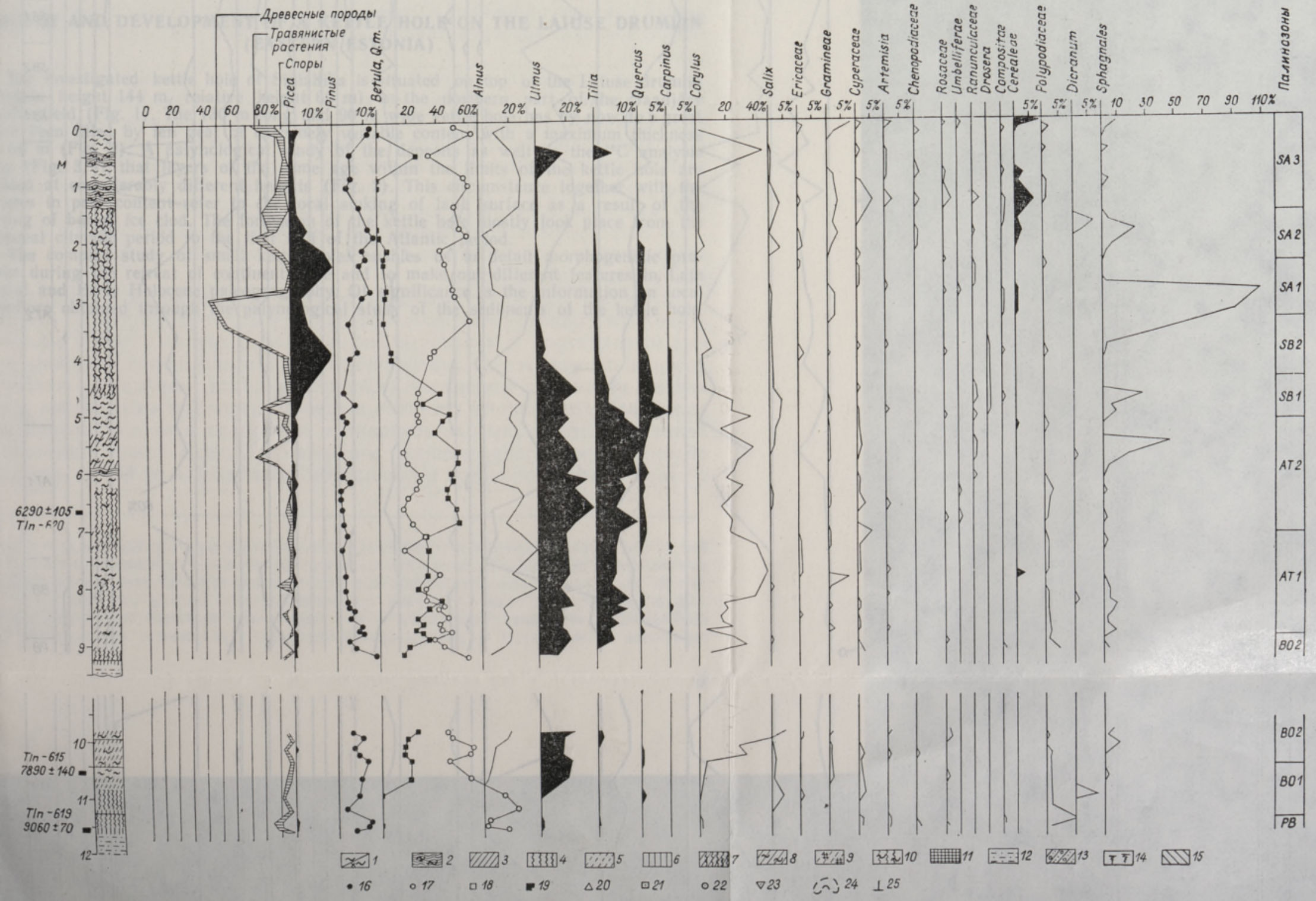

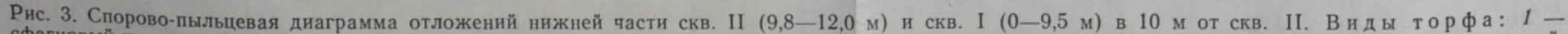

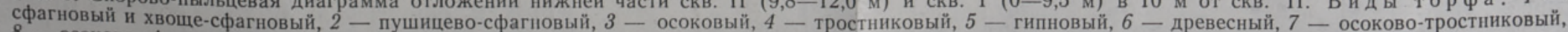

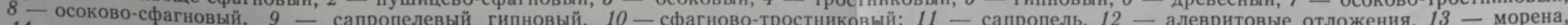

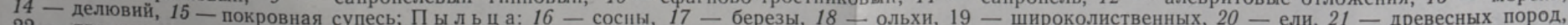

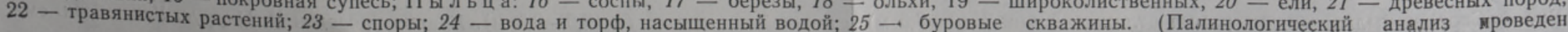

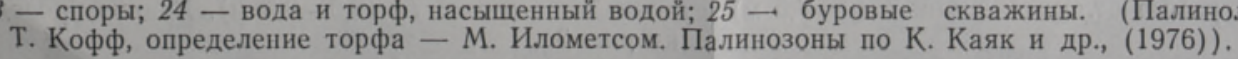




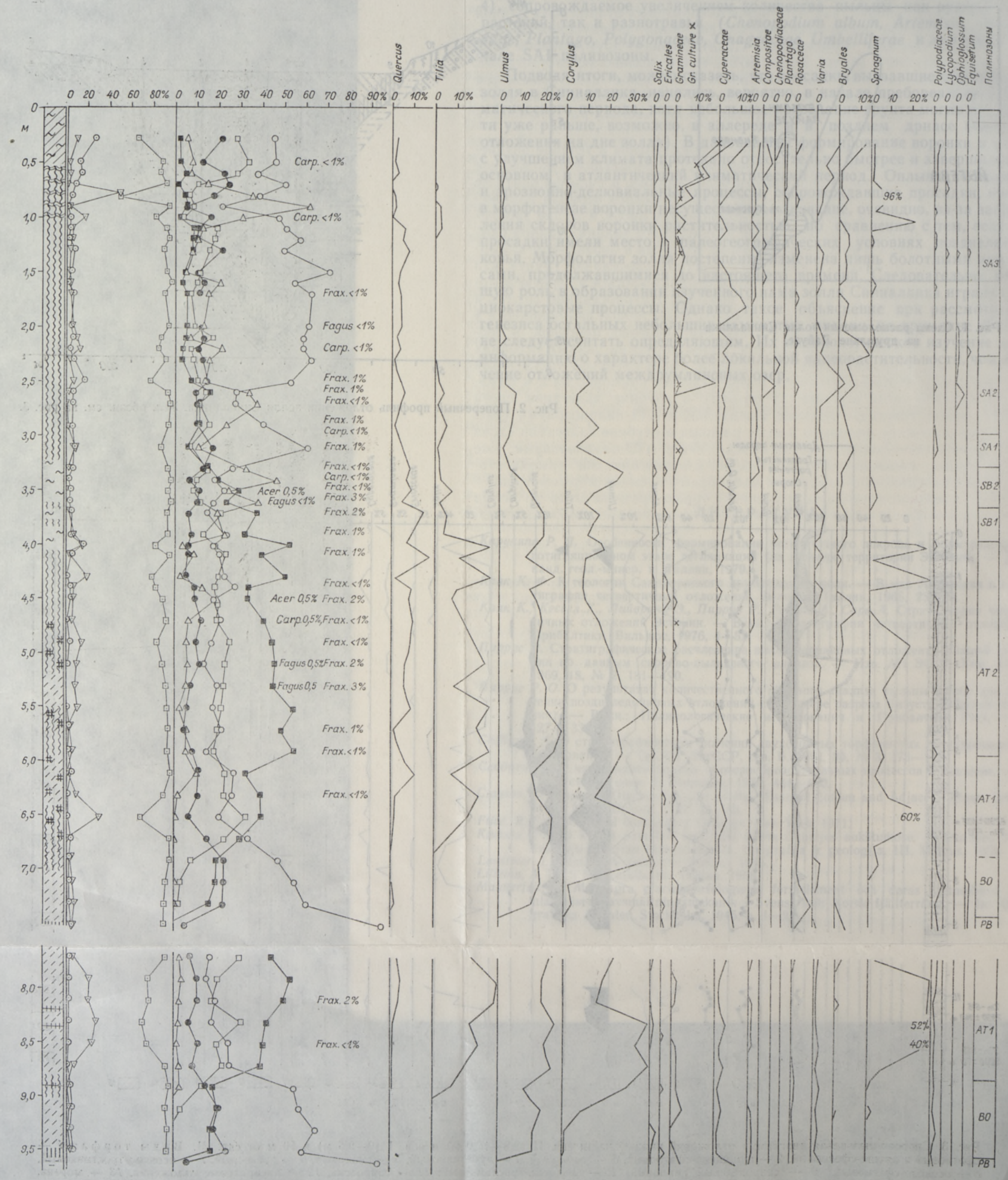

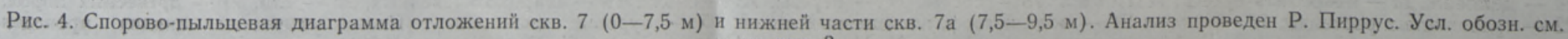
на рис. 3 . 
Pirrus, R., Rõuk, A.-M. Uusi andmeid Soitsjärve nõo geoloogiast. - Rmt.: Eesti NSV saarkõrgustike ja järvenõgude kujunemine. Tallinn, 1979, 118-144.

Whittlesey, C. On the drift cavities, or "potash kettles" of Wisconsin. - In: Proceedings of the American Association for the Advancement of Science, 30th meeting 1859. $1860,297-301$.

$\begin{array}{cc}\text { Институт геологии } & \text { Поступнла в редакцию } \\ \text { Академии наук Эстонской ССР } & 18 / \mathrm{IV} 1985\end{array}$

Институт истории

Академии наук Эстонской ССР

Reet PIRRUS, A.-M. ROUK, Tiiu KOFF

\section{LAIUSE SINIALLIKA SÖLLI EHITUS JA ARENG}

Väikeste sulglohkude kompleksne uurimine võimaldab täpsustada morfogeneetiliste protsesside kulgu mandrijää taandumise ajal ning selgitada hilisjääaegse ja varaholotseense paleogeograafia erijooni. Käsitletav Siniallika söll on üks paljudest Saadjärve voorestikus leiduvatest. Ta asub voorestiku pōhjaosas Laiuse voore lael (joon. 1). Nüüdisajaks on lehtritaoline nõgu suures osas täitunud madalsooturbaga, mille maksimaalne paksus on $11,6 \mathrm{~m}$ (joon. 2). Setete palünoloogilise uurimise ning ${ }^{14} \mathrm{C}$ analüüsi andmeil (joon. 3,4$)$ arvatakse, et vaadeldava glatsiokarstilise nõo moodustumine toimus põhilisèlt holotseeni esimesel poolel. Oluliseks võib pidada ka väikeste sulglohkude setete palünoloogiliste andmete informatiivsust lokaalse paleotaimkatte kohta.

\section{Reet PIRRUS, A.-M. ROUK, Tiiu KOFF}

\section{GEOLOGY AND DEVELOPMENT OF A KETTLE HOLE ON THE LAIUSE DRUMLIN (EASTERN ESTONIA)}

The investigated kettle hole of Siniallika is situated on top of the Laiuse drumlin (absolute height $144 \mathrm{~m}$, relative height $60 \mathrm{~m}$ ) in the northern part of the Saadjärv drumlin field (Fig. 1). The $130 \mathrm{~m}$ long and $90 \mathrm{~m}$ wide kettle hole has by now to a great extent been filled by fen peat of extremely variable content with a maximum thickness of $11.6 \mathrm{~m}$ (Fig. 2). A palynological study of the deposits as well as the ${ }^{14} \mathrm{C}$ analysis show (Fig. 3,4) that layers of the same age within the limits of the kettie hole are situated at considerably different heights (Fig. 2). This circumstance together with the changes in peat content refer to the local sinking of land surface as a result of the melting of buried ice clod. The formation of the kettle hole mostly took place from the preboreal climatic period to the first half of the Atlantic period.

The complex study of small kettle holes enables us to detail morphogenetic processes during the retreat of continental ice and to make out different features in Late Glacial and Early Holocene paleogeography. Of significance is the information on local paleoflora obtained through the palynological study of the sediments of the kettle hole. 